\title{
Meeting Teachers' and Learners' Perceptions on Mobile Learning: A Case of Indonesian Vocational High School in Surakarta City
}

\author{
Budi Setiawan*, Sunardi, Gunarhadi, Asrowi \\ Doctoral Program of Educational Science Department, Faculty of Education and Teacher Training, Sebelas Maret University, Indonesia
}

Received December 9, 2019; Revised December 30, 2019; Accepted February 25, 2020

Copyright $\odot 2020$ by authors, all rights reserved. Authors agree that this article remains permanently open access under the terms of the Creative Commons Attribution License 4.0 International License

\begin{abstract}
Information and communication technology (ICT) has become the main resource to be devoted for most countries in this world. The government of Indonesia has made a regulation by the minister of education and culture in term of implementing curriculum 2013 which includes student center learning and scientific approach as the basis of ICT application. This study discusses the perception of teachers and learners regarding to the implementation of mobile learning in vocational high school. It is a mixed method study where undertakes interviews and surveys coming from two different schools. In analyzing the teachers and learners' perceptions towards implementation of mobile learning, it was used unified theory of acceptance and use of technology (UTAUT) as the guiding model. The data from the survey was analyzed by using SPSS, while finding the contributors key was done by applying percentage analysis. The findings showed that most of teachers and learners at vocational high school in Surakarta city are familiar with mobile ICT. They are capable to operate and use it for some purposes such as; downloading educational material, search for definitions of words or terms, and send assignments to accomplish the learning goals.
\end{abstract}

Keywords Teacher Perception, Student Perception, Mobile Learning, Outcomes

\section{Introduction}

The perception of the users has been noted as the major influences of new technology (Venkatesh, Morris, Davis, \& Davis, 2003) [46]. Factors that influence educators to incorporate innovative technologies along with the policies, environment, views, and support into the classroom have been assessed by some studies (Sang, Valcke, Braak, \&
Tondeur, 2010) [40], (Toraum, 2015) [44]. The developments of technology as they have done in every field influenced the system of education. It brings an influence about to apply computer in the education training and its application within the education system (Murathan \& Kaya, 2016) [33]. Small number of studies about integrating mobile learning into the instructional process used by the teachers as the key elements to centre have been addressed (Aubusson, Schuck, \& Burden, 2009) [5]. (Lefoe, Olney, Wright, \& Herrington, 2009) [28] and (Seppala \& Alamaki, 2003) [42]. By inclining the focus of studies into the learner adoption towards mobile learning in the past by researchers, their perception has been put aside (Uzunboylu \& Ozdamli, 2011) [45]. Mobile learning becomes the new way of e- learning as becoming the latest trend in education field. Dominant technologies handled in any educational provisions is namely as m-learning (Park, Nam, \& Cha, 2012) [37]. The traditional classroom can be put aside by using mobile devices to continue learning without face to face meeting physically between teacher and students. Through online learning, it opens opportunity for them to relate informal learning experiences as adding its complement and value (Motiwalla, 2007) [32]. The chances given more to the students in m-learning lead them to be able to access course materials, become active participants, and share ideas (Nassuora, 2012) [35], gain guidance from educators (Crawford, 2007) [11], and get feedback and formative evaluation (Ciampa, 2014) [10].

Mobile learning is varied on its definition depending on the mobile device application, users' mobility, and the connection between E- learning and mobile learning. It relies on the wireless support to conduct remote and timeless learning process. Employing wireless devices such as; smart phone, PDA, palmtop, iPod, Laptop, USB keys and digital camera in the instructional process is called as mobile learning technology (Naismith, Lonsdale, Vavoula, \& Sharpless, 2004) [34]. Provision of training 
and education using smart phone, palmtops, handhelds, and PDAs as the main focus is defined as mobile learning technology (Keegan, 2005) [23]. M- Learning is the new form and updated trend of e- learning in vocational high school education. Enhancing learning process which focus on architecture system has been adopted by some studies in m-learning (Bomsdorf, 2005 [6]; Capuano, Gaeta, Miranda, \& Pappacena, 2005 [7]; Sharma \& Kitchens, 2004) [41]. Other studies emphasized their research on technology connected to enablers (Huang, Lin, \& Chuang, 2007) [16]. Mobility and ubiquity become the main crucial features in $\mathrm{m}$ - learning. The learning on the go is called as mobility, while ubiquity is the access of technologies wherever and whenever needed. The learning activities covering interaction among teacher- students, conversation, and decision making also include as the feature in m-learning approach (Kukulska-Hulme, 2009) [26]. The significant growth of technology applied in m-learning at the higher education level is affected by the ascending demand on mobile devices, mobile wireless technology, low budget of mobile devices, and multiple usages (pictures capturing, MMS, SMS, internet access, social media, data storing, and audio/ video recording). The adoption of m-learning on some studies to improve the learning process focused on the architectures system (Bomsdorf, 2005 [6]; Capuano, Gaeta, Miranda, \& Papacena, 2005 [7]; Sharma \& Kitchens, 2004) [41]. Related technology solely became the basis works of other studies (Huang, Lin, \& Chuang, 2007 [16]; Liu, Han, \& Li, 2010 [29]; Tagoe \& Abakah, 2014) [43]. On the other hand, narrow understanding on the influence of students' intention to adopt m- learning may occur as the result of limitation on acceptance of related technology (Hashim, tan \& Rashid, 2015) [14]. As the reason above, it is considered to figure out other factors that may influence students' motivation to use it instead of technology factor. Several studies have presented learning activities using $\mathrm{m}$-learning in wide applications, such as language courses (Hsu, Hwang, \& Chang, 2013) [17], Medical Science (Pimmer, Mateescu, Zahn, \& Genewein, 2013 [38]; Wu, Hwang, Su, \& Huang, 2012) [49], Science (Lan \& Huang, 2012) [27], and social science (Chiou, Tseng, Hwang, \& Heller, 2010) [8]. Adopting m-learning into the instructional process leads the students to be active, collaborative, gaining high scores, and have control over the learning (Al- Fahad, 2009; Mcconatha, Praul, \& Lynch, 2008) [2]. In brief, the values of learning approach, collaborative learning environment, and maximize students' interaction and flexibility will include into the teachinglearning activities if $\mathrm{m}$ - learning is applied effectively. Students' perception on m-learning explored by conducting related research (Jacob \& Isaac, 2008) [20], satisfaction (Ismail, Gunasegaran, Koh, \& Idrus, 2010) [19], involvement (Abas, Lim, \& Woo, 2009) [1], readiness (Hussin, Manap, Amir, \&Krish, 2012) [18], and achievement (Nordin, Embi, Yasia, Rahman, \& Yunus, 2010) [36] showed that students' feel that m-learning as an additional learning support that encourages them to be motivated, develop interaction, and improve their learning process.

The students' perception became the focus of previous studies related to m-learning, satisfaction, involvement, readiness, and achievement indicating that it motivates students to have fosters connection and improve their learning process. Accordingly, our research question explored both teachers and students perceived feedback as the perceptions. The following research questions were developed to address the goal of the research.

- What are the self- regulated factors questions regarding to teachers' and students' perceptions towards mobile learning?

- What are the factors influencing teachers' and students' perceptions on the application of mobile learning in vocational high school?

\section{Material and Method}

\subsection{Research Subject}

The sample of this study consists of two (2) vocational high schools in Surakarta city. A sample of the teachers and students was taken from them. The students were selected mainly from 12 (twelve) grades. Twenty-five (25) students were randomly chosen from each school. The questionnaire is in line with the research goal. The guiding theory (UTAUT) is used as a guidance to set theories and models in the tested questions and survey. It spreads by range of Likert scales (1-5) on the survey instrument from "strongly agree" to "strongly disagree" used as the construct items for all (Venkatesh, Morris, Davis, \& Davis, 2003) [46]. Then, the data was analyzed by using SPSS for descriptive and inferential statistics.

\subsection{Population and Sample}

The sample of this study consists of two (2) vocational high schools in Surakarta city. A sample of the teachers and students was taken from them. The students were selected mainly from 12 (twelve) grades. Twenty-five (25) students were randomly chosen from each school. Productivity is technically an understanding of production efficiency, especially in the use of science and technology.

\subsection{Data Collection Method}

Mixed method approach is used to design the research by compromising interviews and survey. To offer a better comprehension of the topic discussed, it is necessary to get quantifiable data related to recent use, perceptions, and application by having data triangulation. Open- ended response question is applied on the survey instrument as the qualitative data. It is relied on the survey instrument 
constructed by (Wang \& Shih, 2008) [47] and (Venkatesh, Morris, Davis, \& Davis, 2003) [46]. It also applied UTAUT instrument utilized by some researchers (Anderson and Schwager, 2004) [4], (Moran, 2006) [31] and (Wang \& Shih, 2008) [47].

\section{Results}

\subsection{Findings of Research from Self-Generated Questions}

Regarding to the students' perceptions in the study, there were two schools participating to obtain the data. It consists of two state or public vocational high schools meeting national education standard by the same accreditation level in rural sub- urban areas. The students as the sample coming from each school were 25 in number. They were taken from 12 grade only by age of 16- 17 years old. In total, there were 50 students from those two schools covering 32 female students and 18 male students. Dealing with the teachers' perceptions, there were 10 teachers coming from two schools in total. 5 teachers from each school taking a part in this study by age variance from 2635 . In addition, they have been teaching about for more than two years.

The following were the findings of the research:

\subsubsection{Downloading Educational Materials}

If the downloading features of mobile phones are properly used to get various kinds of materials, they will improve their learning capabilities (Kafyulilo, 2012) [21]. It shows that only $21 \%$ percent of the students have downloaded any materials related to their study into their mobile phone. It means that others having the access for mobile devices to do mobile learning use it for another purpose or download other materials.

Meanwhile, the teachers are able to download the materials in term of video and present it in the instructional process by using LCD projector. $80 \%$ of the teachers have the capability to download the educational materials properly by using mobile devices. The rest, which is $20 \%$ are not able to do as well. It becomes big opportunity and potential for the teachers to implement mobile learning in the environment of educational perspective by exploring and maximizing the benefits of downloading the materials.

\subsubsection{Searching for Definition of Terms or Words}

There is a possibility to go deeper on comprehending of a subject by using mobile learning devices. It also has meaning that the provider of information coming from the mobile appliances. The responses from the teachers and students showed how its tool assisting them in finding out or getting the information needed. $92 \%$ of the students performed that they were easily getting the words or terms by mobile devices while $18 \%$ could not. The obstacle faced by the students at $18 \%$ category as they do not have their own personal mobile devices. Consequently, they need to borrow others' mobile equipment used in turn. Most of them are literate in terms of words or terms search.

Meanwhile, $98 \%$ of the teachers have found no problems in finding the definition of words or terms by using mobile devices, while only $2 \%$ of them are not. They have less pressure about preparation before going into the class as many resources available. It contributes on the effectiveness of instructional process that both teachers and students are in balance to this aspect.

\subsubsection{Sending Assignments by Email}

The chances of using mobile devices to interact with others, share knowledge, send email, and get its feedback by the teachers to the students become one of interesting aspects in mobile learning (Gikas \& Grant, 2013) [13]. Seen from the students' accessibility towards internet, $70 \%$ of them can send email by using their mobile while the rest, $30 \%$ are incapable. It was found that $90 \%$ of them to be active internet user but less of them, precisely $70 \%$, but most of them make social media to be more crucial than email. It is necessary to use social media as a medium to conduct mobile learning. On the other hand, $51 \%$ of the teachers stated to be active email users while the $49 \%$ stated no. it can be assumed that most probably many of them do not make sure of it well as a media mobile learning. Therefore, it is recommended not so frequently using email as a medium of communication between teachers and students in a mobile device education.

It is advantageous to use these mobile devices in the learning process in the educational field (Al- Khanjar et al, 2015) [3]. The students have a capability to access to download any materials or application in supporting their learning effectively. Those three aspects in the selfgenerated questions imply that teachers and students' perceptions learning are significantly positive regarding to achieve the instructional goals effectively through mobile learning. The description of three aspects in self- generated perceptions can be seen below.

\subsubsection{Social Media Sites Access}

Social media has become the centre of trend and very popular among the youth. They are attached to these sites becoming part of daily life. 100\% students stated that they have fully access on social media sites through mobile devices. It means that it opens chances more to include any concepts by using social media as the way to transfer. It is necessary for the educators or teachers to take benefit from social media as mobile education in interesting and appealing way for youngsters.

From the teachers' point of view, it showed that $100 \%$ of them could access social media sites by mobile device. It becomes positive point in that they have capability to teach by using social media. Both teachers and students meet in balance about accessing social media. The effect of mobile technologies on learning and teaching is in line with social 
media in the form of Twitter, Skype, and Blogs for giving better learning (Gikas \& Grant, 2013) [13]. The overall usage of technology through mobile phones by students to facilitate them in learning process can be seen in the figure below.

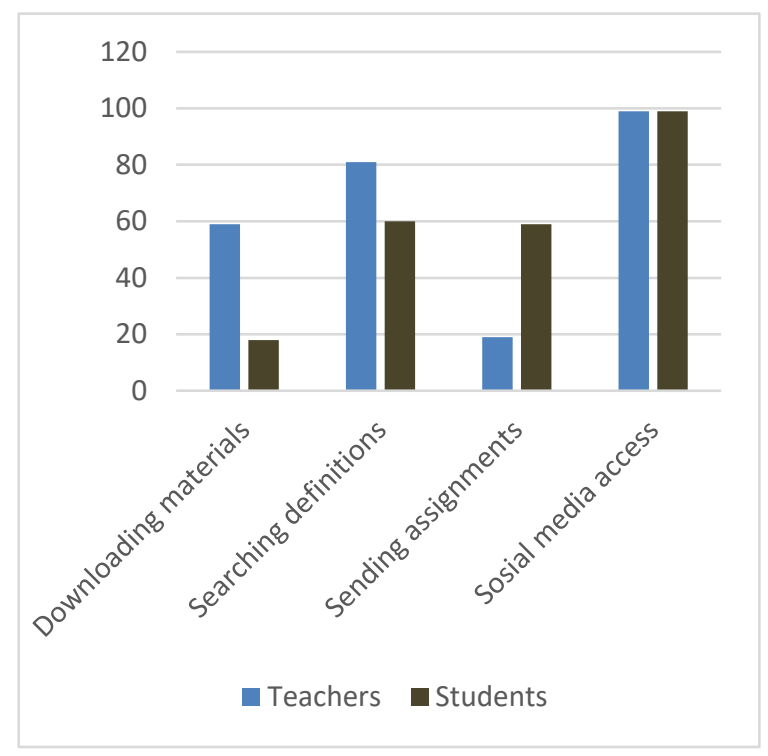

Figure 1. Self-generated Questions

\subsection{Findings from UTAUT}

In predicting the usage and behavior on the adoption of technology, there are variety of models or theories applied. Developed by Venkatesh, Davis, and Davis (2003) [46], the UTAUT was used to examine students' and teachers' behavioral intentions to use and adopt mobile learning in the instructional process. It includes of four key constructs (Venkatesh, et al 2003) [46]:

\subsubsection{Performance Expectancy}

\subsubsection{The Benefit of Mobile Technology to Learning}

It is defined as what the people believe by using technology/ information system to help them in gaining positive results from job performance. Due to their usefulness, mobile phones have to be used in teaching and learning process (Kihwele \& Bali, 2013) [24]. This is the case with these responses where $81 \%$ of the students agree that mobile learning would bring beneficial to their studies. $19 \%$ of the students' state to be disagree that it will be useful.

$90 \%$ of the teachers declared to be agree and $10 \%$ strongly agree that mobile learning will contribute positively in their instructional process. In total $100 \%$ of the responses, it can be inferred that they have positive responses to the mobile learning applied on the teachinglearning activities. Both teachers and students agree that mobile learning is useful to gain the goals.

\subsubsection{Gaining Efficient Teaching Activities}

Some researches implied that electronic media in any forms support the multitasking activities (Jacobsen \& Forste, 2011 [20]; Karpinski et al, 2013 [22]; Kirscher \& Karpinski, 2000 [25]; Wood et al, 2012 [48]) and taskswitching (Rosen et al, 2013) [39]. By this case, it was obviously clear that m-learning devices are enable both teachers and students to gain efficient learning activities through varied built in features. $56 \%$ of the students claimed to be agree and $44 \%$ of them strongly agree to state about the accomplishment of effective learning activities through m- learning.

Meanwhile, the teachers declared that $38 \%$ of them to be agree and the rest of $62 \%$ as strongly agree dealing with the statement as m-learning be less time consuming in assisting them for teaching activities accomplishment. There is big potential to apply m-learning in the instructional process on the benefits for both sides. The overall aspects and percentage of technology in expected performance are described below.

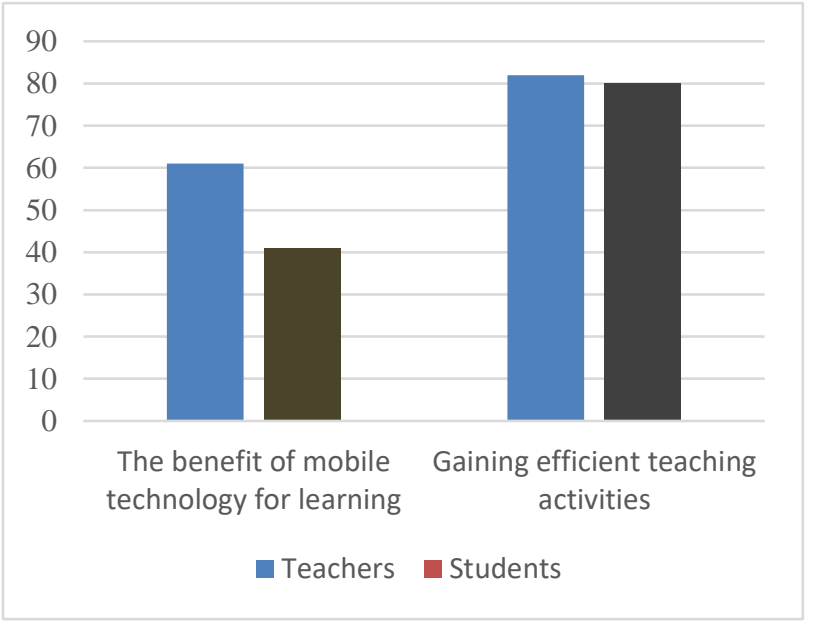

Figure 2. Performance Expectancy

\subsubsection{Effort Expectancy}

\subsubsection{Ease of M-learning Devices Operation}

It is the expectancy degree of ease related to the use of technology/information system. Easiness to use is believed as the measure of the degree from individual to be free from effort (Chin \& Todd, Chang \& Tung, 2008) [9]. 64\% of the students agree and $30 \%$ of them strongly agree about stating the easiness to operate or use mobile devices. Only $6 \%$ of them found that it was difficult. Whereas, the teachers in a range of $29 \%$ said to agree and $59 \%$ in strongly agree perception about finding the mobile devices is not difficult to be used. $12 \%$ of the teachers stated to be disagree with the ease usage of mobile learning devices. In brief, both sides can find the advantages of mobile learning applied in the learning process.

\subsubsection{Acquiring Skills from Mobile Devices}

It is believed that m-learning devices will expand the teachers and students' skills and capabilities. It is 
accordance with the result of the survey showing that $80 \%$ of the students agree and $20 \%$ of them strongly agree for the contribution of m-devices adding their skills. The teachers performed mostly typical responses with the students to say by percentage of $90 \%$ agree and $10 \%$ strongly agree with the role of m-devices to support the acquaintance of skill for them. The two aspects resulted in effort expectancy are presented as follow.

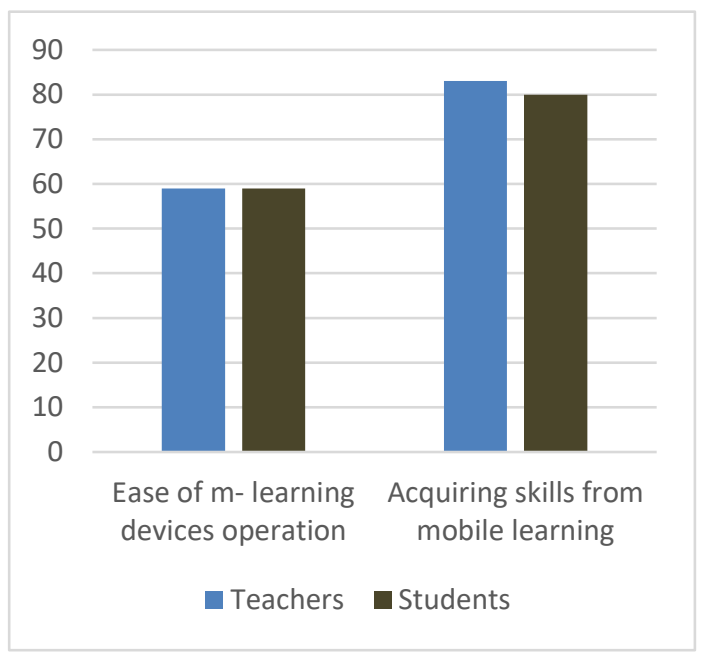

Figure 3. Effort Expectancy

From the graph in figure 5 above, it can be seen that they are on the same point of view to see how m-devices will promote or support them to be more skilful.

\subsubsection{Social Influence}

\subsubsection{Influencing People on Behavioral Change}

The extent that users perceive as seems to be crucial for others should apply a new information system. Administrators, principles, and peers are the people who influence teachers' behavior. Research and wide coverage reading would be encouraged by teachers, while colleagues would make discussion to some topics of any events. $51 \%$ of teachers agree and $31 \%$ strongly agree that well informed people on mobile education technology devices influence their behavior. The rest of the responses stated that $10 \%$ strongly disagree and $8 \%$ disagree towards mobile technology on learning may change the behavior.

From the students' perspectives in term of their responses on behavioral change and mobile learning, it is stated that $58 \%$ of the students agree and $12 \%$ strongly agree that people who change their behavior should use mobile learning devices for education. If it is given space, the external factor can give effect on education by applying of mobile learning. Then, $20 \%$ disagree and $10 \%$ strongly disagree with the statement.

\subsubsection{Support for Mobile Learning}

Students believed that their school will fully support the application or adoption of m-learning into the school policies. It can be reflected from the results of responses showing that $70 \%$ of students agree and $30 \%$ of them strongly agree about how school will contributes on its program through supporting decision by the principal and related parties. While 39\% teachers agree and 61\% strongly agree that their school will give assistance on the use of m-learning to be integrated on the learning process. The percentage results on how technology give effects on social life is shown on figure 4 below.

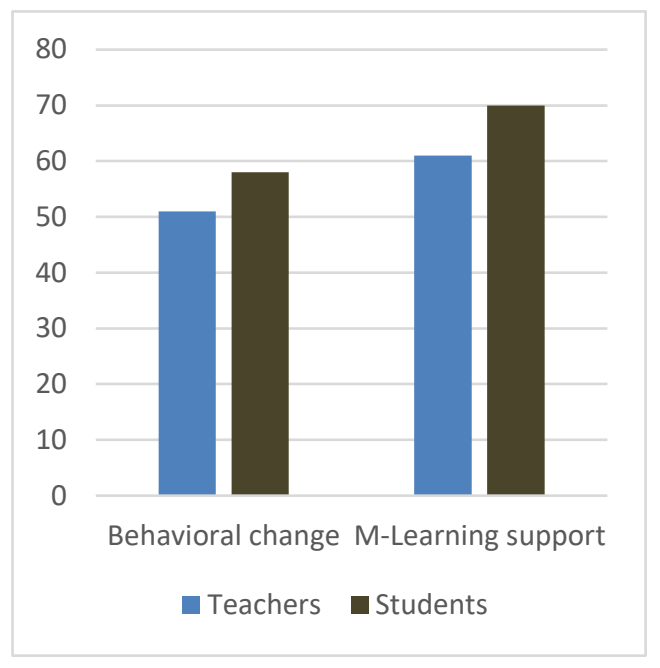

Figure 4. Social Influence

These responses show how both teachers and students have big expectations on school to carry out the program by means of supporting policies. The vital aspects influencing the students to utilize mobile devices as the learning tool are the support from the stakeholders and environment.

\subsubsection{Facilitating Conditions}

\subsubsection{M-learning Resources}

The degree of belief that technical and organizational infrastructure are available to support the use of any system. $70 \%$ of the students agree and $22 \%$ strongly agree that they have the sources for mobile learning. It is 0nly $8 \%$ of the students stated to be disagree as they have financial limitations with the access for mobile phone. $89 \%$ of the teachers agree and $11 \%$ strongly agree that they have proper sources to make function of mobile phones. It is not only in term of mobile devices but also positive attitude and knowledge. To sum up, the cost of purchasing devices can be the obstacles by teachers and students to be used (Crompton, 2013).

\subsubsection{M-learning Knowledge}

It is needed to have knowledge about using related mobile devices on m-learning with $95 \%$ agree and 5\% strongly agree stated by the students. They have to understand about the information on its usage properly. While the teachers stated that it is a necessary to have the initial knowledge on how to operate m-learning appropriately by the indication of $100 \%$ agree on the 
necessity of having prior information and be knowledgeable for m-learning. Those two aspects on facilitating conditions regard to technology and learning are presented on the figure 5 as follow.

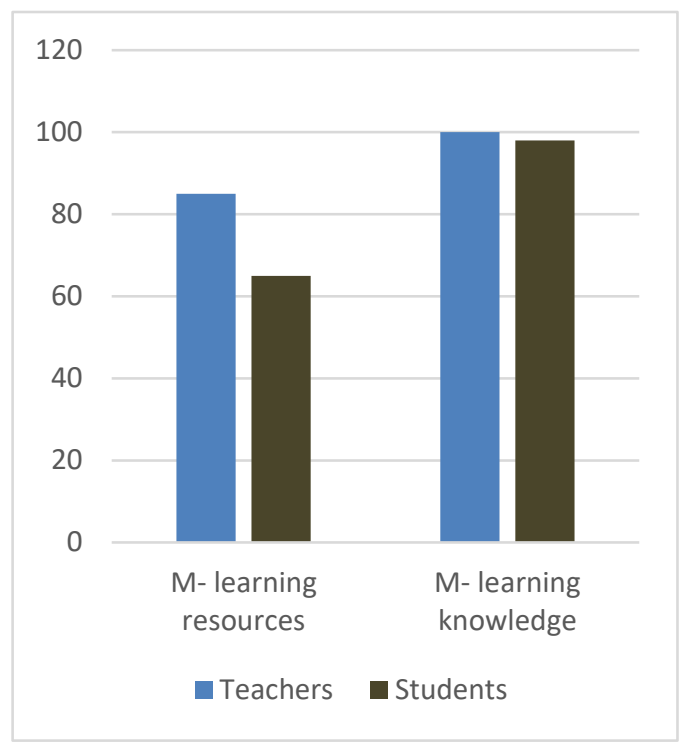

Figure 5. Facillitating Conditions

\section{Conclusions}

The results of the survey showing that the vocational high schools in Indonesia is ready to conduct instructional process supported by mobile learning. The findings showed that most of the teachers and students are familiar with mobile ICT. This technology based tools or devices are owned and used by many people in term of mobile phones. The majority both teachers and learners can search educational materials, find the definition of words or terms, and send assignments by using mobile devices with ICT. Mobile learning integration into schools has wide coverage of beneficial aspects seen from teacher and education in general. The upcoming research should be done focusing on gender, social economy status, and parents' job and educational background to see if the local government, central government by minister of education and culture policies needs to review.

\section{REFERENCES}

[1] Abbas, Z. W., Lim, T., \& Woo, T.-K. Mobile learning initiative through SMS: A formative evaluation. ASEAN Journal of Open and Distance Learning. 1(1), 49 58, 2009.

[2] Al- Fahad, F.N. Students' attitudes and perceptions towards the effectiveness of mobile learning in King Saud University, Saudi Arabia. Turkish Online Journal of Distance Education, 8(2), 111 119, 2009.

[3] Al- Khanjar, Z., I.Z. Al-Kindi \& N. Kraiem. Developing Educational Mobile Application Architecture Using SOA
International. Journal of Multimedia and Ubiquitous Engineering, 10 (9): 247-254, 2015.

[4] Anderson, J., \& Schwager, P. SME Adoption of Wireless LAN Technology: Applying the UTAUT Model. 7th Conference of the Southern Association for information System, 2004.

[5] Aubusson, P., Schuck, S., \& Burden, K. Mobile Learning for Teacher Professional Learning: Benefits, Obstacles and Issues. ALT-J: Research in Learning Technology, 17(3), 233-247, 2009.

[6] Bomsdorf, B. Adaptation of Learning Spaces: Supporting Ubiquitous Learning in Higher Distance Education. In Mobile Computing and Ambient Intelligence. 2005.

[7] Capuano, N., Gaeta, M. Miranda., S., \& Pappacena, L. A System for Adaptive Platform-Independent Mobile Learning. Mobile Learning Anytime Everywhere 53, 2005.

[8] Chiou, C.-K., Tseng, J. C., Hwang, G.-J., \& Heller, S. An adaptive navigation support system for conducting contextaware ubiquitous learning in museums. Computers \& Education, 55(2), 834 845, 2010.

[9] Chin, W.W., Todd, P.A. On the Use, Usefulness, and Ease of Structural Equation Modelling in MIS Research. A Note of Caution. MIS Quarterly, 19(2), 210-237, 1995.

[10] Ciampa, K. Learning in a mobile age: investigation of student motivation. Journal of Computer Assisted Learning, 30(1), 82 96, 2014.

[11] Crawford, V.M. Creating a powerful environment with networked mobile learning devices. Educational Technology, 47(3), 47 50, 2007.

[12] Crompton, H. A Historical Overview of M-learning: Toward Learner- centered Education. In Berge, Z. L. and Muilenberg, L.Y. (Eds). Handbook of Mobile Learning. (New York, NY: Routledge) pp.3-14, 2013.

[13] Gikas, J., \& Grant, M.M. Mobile Computing Devices in Higher Education: Student Perspectives on Learning with Cellphones, Smartphones, \& Social Media: The Internet and Higher Education, (19), 18-26, 2013.

[14] Hashim, K. F., Tan, F. B. \& Rashid, A. Adult learners' intention to adopt mobile learning: A motivational perspective. British Journal of Educational Technology, 46(2), $381390,2015$.

[15] Huang, J,-H., Lin, Y,-T., \& Cheng, S,- C. Toward interactive mobile synchronous learning environment with context awareness service. Computers \& Education, 63, 237 336, 2008.

[16] Huang, J. H., Lin, Y.R., \& Chuang, S.T. Elucidating User Behaviour of Mobile Learning. A Perspective of the Extended Technology Acceptance Model. The Electronic Library, 25 (5).585-598, 2007.

[17] Hsu, C.-K., Hwang, G.-J., \& Chang, C.-K. A personalized recommendation based mobile learning approach to improving the reading performance of EFL students. Computers \& Education, 63, 327 336, 2013.

[18] Hussin, S., Manap, M. R., Amir, Z., \& Krish, P. Mobile learning readiness among Malaysian students at higher learning institutes. Asian Social Science, 8(12), 276 283, 2010. 
[19] Ismail, L., Gunasegaran, T., Koh, P., \& Idrus, R. M. Satisfaction of distance learners towards mobile learning in the Universiti Sains Malaysia. Malaysian Journal of Educational Technology, 10(2), 47 54, 2012.

[20] Jacob, S. M., \& Isaac, B. The mobile devices and its mobile learning usage analysis. In Proceedings of the international multiconference of engineers and computer scientists (pp. 782 787) International Association Engineers, 2008.

[21] Kafyulilo, A. Access, Use and Perceptions of Teachers and Students towards Mobile Phone as a Tool for Teaching and Learning in Tanzania. Educational and Information Technologies Journal, 2012.

[22] Karpinski, A. C., Kirschner, P. A., Ozler, I., Mellot, J. A., Ochowo, P. An exploration of social networking site use, multitasking, and academic performance among United States and European university students. Computers in Human Behavior, (29) 1182 1192, 2013.

[23] Keegan, D. Mobile Learning: The Next Generation of Learning: Distance Education International, 2005.

[24] Kihwele, J.E., \& Bali, T.A. L. The Perceptions of Teachers, Parents and Students on the Effects of Mobile Phone Use on Student Learning in Tanzania: Journal of Education and Practice, 4(25), 101-106, 2013.

[25] Kirschner, P.A., \& Karpinski, A.C. Facebook and academic performance. Computers in Human Behavior, (26), 1237 $1245,2010$.

[26] Kukulska-Hulme, A. Will mobile learning change language learning? ReCALL, 21(2), 157 165, 2009.

[27] Lan, Y.-F., \& Huang, S.-M. Using mobile learning to improve reflection. A case study of traffic violation. Journal of Educational Technology \& Society, 15(2), 179 193, 2012.

[28] Lefoe, G., Olney, I., Wright, R., \& Herrington, A. Faculty of Development for New Technologies: Puttting Mobile Learning in the Hands of Teachers. In A. Herrington, J. Mantei, I. Olney, \& B. FERRY (Eds.), New Technologies, New Pedagogies: Mobile Learning in Higher Education: Wollongong, Australia: University of Wollongong, 2009.

[29] Liu, Y., Han, S., \& Li, H. Understanding the factors of driving m-learning adoption: A literature review. CampusWide Information Systems, 27 (4), 210 226, 2010.

[30] Mcconatha, D., Praul, M., \& Lynch, M. J. Mobile learning in higher education: An empirical assessment of a new educational tool. Turkish Online Journal of Educational Technology, 7(3), 15 21, 2008.

[31] Moran, M. College Learners' Acceptance of Tablet Personal Computers: a Modification of the Unified Theory of Acceptance and Use of Technology Model. (Capella, Italy: Capella University), 2006.

[32] Motiwalla, L. F. Mobile learning: A framework and evaluation. Computers \& education, 49 (3), 581 596, 2006.

[33] Murathan, T., \& Kaya, O. Evaluation of Sports Trainers Perceptions on Computer Aided Education Related to the Attitudes toward Learning. Universal Journal of Educational Research 4(2): 416-421, 2016.

[34] Naismith, L, Lonsdale, P., Vavoula, G., \& Sharples, M. Literature Review in Mobile Technology and Learning Report 11. Future Lab Series, 2004.
[35] Nassuora, A. B. Students' acceptance of mobile learning for higher education in Saudi Arabia. American Academic \& Scholarly Research Journal, 4(2), 24 30, 2012.

[36] Nordin, M. N., Embi, M. A., Yasin, R. M., Rahman, S., \& Yunus, M. M. The mobile learning readiness of the postgraduate students. In Proceedings of 2010 of EABR \& ETLC Conference, 2010.

[37] Park, S.Y., Nam, M,-w., \& Cha, S.-B. University students' behavioral intention to use mobile learning: Evaluating the technology acceptance model. British Journal of Educational Technology, 43(4), 592 605, 2012.

[38] Pimmer, C., Mateescu, M., Zahn, C., \& Genewein, U. Smartphones as multimodal communication devices to facilitate clinical knowledge processes: Randomized controlled trial. Journal of Medical Internet Research, 15(11), 2013.

[39] Rosen, L. D., Carrier, M., Cheerver, N. A. Facebook and texting mode me do it: Media-induced task- switching while studying. Computers in Human Behavior, (29), 948 958, 2013.

[40] Sang, G., Valcke, M., Braak, J., \& Tondeur. J. Learner Teachers' Thinking Process and ICT Integration: Predictors of Prospective Teaching Behaviour with Educational Technology. Computers and Education, 54(1), 103-112, 2010.

[41] Sharma, S. K., \& Kitchens, F. L. Web services architecture for m-learning. Electronic journal on E-Learning, 2(1), 203 216, 2004.

[42] Seppala, P., \& Alamaki, H. Mobile Learning in Teacher. Training. Journal of Computer- assisted Learning, 19, 133-335, 2003.

[43] Tagoe, M., \& Abakah, E. Determining distance education students' readiness for mobile learning at University of Ghana using the theory of planned behavior. International Journal of Education and Development using Information and Communication Technology, 10 (1), 91 106, 2014.

[44] Toraum, J. E-Learning and Distance Education in Nigeria. Oju online Journal of Education, 7 (4), 1-10, 2015.

[45] Uzunboylu, H., \& Ozdamli, f. Teacher Perception for M-learning: Scale, Development and Teachers' Perception. Journal of Computer- assisted Learning, 27(6), 544-556, 2011.

[46] Venkatesh, V., Morris, M., Davis, G., \& Davis, F. User Acceptance of Information Technology towards a Unified View. MIS Querty, 27 (3), 425- 478, 2003.

[47] Wang, Y., Shih, Y. Why do People Use Information Kiosk? A Validation of the Unified Theory of Acceptance and Use of Technology. Government Information Quarterly, 26(1), 158-165, 2008.

[48] Wood, E., Zivcakova, L., Gentile, P., Archer, K., De Pasquale, D., \& Nosko, A. Examining the impact of off-task multi-tasking with technology on real-time classroom learning. Computers \& Education, 58(1), 365 374, 2012.

[49] Wu, P.-H., Hwang, G.-J., Su, L.-H., \& Huang, Y.-M. A context- aware mobile learning system for supporting cognitive apprenticeships in nursing skills training. Journal of Educational Technology \& Society, 15(1), 223 22, 2012 